\title{
Genetic parameters and principal components analysis of breeding value for birth and weaning weight in Egyptian buffalo
}

\author{
Mohamed Mahmoud Ibrahim Salem ${ }^{1, *}$, Amin Mohamed Said Amin², Ayman Fouad Ashour², \\ Mohamed Mohamed El-said Ibrahim², and Mohammed Kotb Abo-Ismail ${ }^{3}$
}

\footnotetext{
* Corresponding Author: Mohamed Mahmoud Ibrahim Salem Tel: +20-3-5915427, Fax: +20-3-5922780 E-mail: mmisalem@gmail.com

${ }^{1}$ Department of Animal and Fish Production, Faculty of Agriculture, University of Alexandria, Alexandria, 21545, Egypt ${ }^{2}$ Animal Production Research Institute Agricultural Research Center, Dooki, Giza, 12619, Egypt

${ }^{3}$ Animal science Department, College of Agriculture, Food and Environmental Sciences, California Polytechnic State University, San Luis Obispo, CA 93407, USA

ORCID

Mohamed Mahmoud Ibrahim Salem https://orcid.org/0000-0002-7504-9728 Amin Mohamed Said Amin https://orcid.org/0000-0002-4491-9284 Ayman Fouad Ashour

https://orcid.org/0000-0002-4721-7675 Mohamed Mohamed El-said Ibrahim https://orcid.org/0000-0002-0299-2686 Mohammed Kotb Abo-Ismail https://orcid.org/0000-0002-3407-5663
}

Submitted Aug 15, 2019; Revised Oct 14, 2019 Accepted Dec 21, 2019
Objective: The objectives of the current study were to study the main environmental factors affecting birth weight (BW) and weaning weight (WW), estimate variance components, genetic parameters and genetic trend and to evaluate the variability and relationships among breeding value of BW and WW using principal components analysis (PCA).

Methods: A total of 16,370 records were collected from 8,271 buffalo calves. Genetic parameters and breeding values were estimated using a bivariate animal model which includes direct, maternal and permanent maternal effects. These estimates were standardized and used in PCA.

Results: The direct heritability estimates were 0.06 and 0.41 for BW and WW, respectively whereas direct maternal heritability values were 0.03 and 0.14 , respectively. Proportions of variance due to permanent environmental effects of dam were 0.455 and 0.280 for BW and WW respectively. The genetic correlation between BW and WWs was weak approaching zero, but the maternal correlation was 0.26 . The first two principal components (PC1 and PC2) were estimated utilizing the standardized breeding values according to Kaiser method. The total variance explained by the first two PCs was $71.17 \%$ in which $45.91 \%$ and $25.25 \%$ were explained by PC1 and PC2, respectively. The direct breeding values of BW were related to PC2 but those of WW and maternal breeding values of BW and WWs were associated with PC1.

Conclusion: The results of genetic parameters and PCA indicate that BW and WWs were not genetically correlated and improving growth traits of Egyptian buffaloes could be achieved using WW without any adverse effect by BW.

Keywords: Genetic Analysis; Growth Traits; Multivariate Techniques

\section{INTRODUCTION}

Water buffalo are important source of meat, high quality milk and skin as well as other by products, not only in Egypt but also in many countries worldwide. Thus, buffalos contribute significantly in agriculture economy and human well-being in these regions. The total number of buffaloes worldwide is about 195.1 million heads, in which $97 \%$ are raised in Asia [1] and 2\% ( 4 million head) are reared in Egypt [1] mainly for milk and meat production. Egyptian buffaloes, known as river buffalo (Bubalus bubalis) contributed 39.2\% and 45.2\% of national total meat and milk production, respectively [1]. As 96\% of buffaloes population in Egypt are owned by small holders, buffaloes play an essential role in rural economy and have challenges in establishing genetic improvement program.

Calf birth weight (BW) is one of the main breeding goals of buffalo breeders, because of its positive relationship with production and reproduction performance. Although, MMI Salem and AMS Amin [2] showed that the stillbirth incidence was similar in either light 
or heavy weights at birth in the Egyptian buffalo, strong genetic correlations between BW and other growth performance traits including weaning and yearling weights were reported in Pakistani Nili-Ravi buffalo [3] and Surti buffalo [4]. in addition, strong genetic correlations between BW and several production and reproduction traits such as milk yield, peak daily milk yield, lactation length, age at first calving and calving interval were reported [5]. Accurate estimations of variance components and genetic parameters such as (i.e. heritability and genetic correlation) for Egyptian buffalo growth performance traits are important to design suitable genetic improvement programs. Principal component analysis (PCA) is a multivariate data technique used to reduce the size of a set of variables by removing repeated information while maintaining the maximum variance-covariance structure of these variables [6]. The PCA has been used in the animal breeding and genetics field to reduce the size of the direct additive genetic covariance matrix in multiple trait models [6,7], and to study the relationship among predicted breeding value [8] as well as population and family structure using genomic data. Thus, the objectives of the current study were to: i) detect the main environmental factors affecting BW [7] and weaning weight (WW); ii) estimate variance components, genetic parameters and genetic trend; iii) evaluate the variability and relationships among breeding value of BW and WWs using PCA .

\section{MATERIALS AND METHODS}

\section{Dataset}

Data were collated from five buffalo experimental herds (ElNattafe El-Gadid, El-Nattafe El-Kadim, Nubariya, Sids and Gimeza) belonging to the Animal Production Research Institute (APRI), Agriculture research center (ARC), Ministry of Agriculture and Land Reclamation, Egypt. A total of 16,370 records were available on 8,327 buffalo calves in which 8,271 and 8,099 records for BW and WW, respectively, were included in the analysis. These calves were born between 1980 and 2018 with pedigree having 188 sires and 2,211 dams (Table 1).

\section{Statistical analyses}

The systematic environmental effects on growth performance traits were examined as fixed effects using least squares methods implemented in general linear model procedure of SAS [9]. These fixed effects included the effects of season of calving (4 seasons), year of calving (39 years), sex (male and female), herd ( 5 herds), gestation length (GL; 4 levels), weight of dam (WD; 5 levels) and parity (14 parities). The effect of GL had 4 classes; between 295 and 325 days with increment of 15 days. Whereas the WD had 5 classes between 300 and $500 \mathrm{~kg}$ with increment of $50 \mathrm{~kg}$. The linear model was fitted as follows:
Table 1. Description of data set for birth and weaning weights of Egyptian buffalo calves

\begin{tabular}{lc}
\hline Item & Number \\
\hline Number of animals in the pedigree & 9,299 \\
Number of animals with records & 8,327 \\
Number of records & 16,370 \\
Number of sires with progeny & 188 \\
Number of sires with progeny and records & 72 \\
Mean number of progeny records per sire & 115.6 \\
Number of dams with progeny & 2,211 \\
Number of dams with progeny and records & 1,373 \\
Mean number of progeny records per dam & 6.06 \\
\hline
\end{tabular}

$$
\mathrm{Y}_{\mathrm{ijklmnop}}=\mu+\mathrm{A}_{\mathrm{i}}+\mathrm{B}_{\mathrm{j}}+\mathrm{C}_{\mathrm{k}}+\mathrm{D}_{\mathrm{l}}+\mathrm{G}_{\mathrm{m}}+\mathrm{W}_{\mathrm{n}}+\mathrm{P}_{\mathrm{o}}+\mathrm{e}_{\mathrm{ijk} k \mathrm{knnop}}
$$

Where, $\mathrm{Y}_{\mathrm{ijk} \text { kmnop }}$, the phenotypic record of BW or $\mathrm{WW} ; \mu$, the effect of the intercept; $A_{i}$, the fixed effect of ith season of calving; $B_{j}$, the fixed effect of $j$ th year of calving; $C_{k}$, the fixed effect of kth sex; $D_{l}$, the fixed effect of lth herd; $G_{m}$, the fixed effect of mth gestation length; $W_{n}$, the fixed effect of nth WD; $\mathrm{P}_{\mathrm{o}}$, the fixed effect of oth parity and $\mathrm{e}_{\mathrm{ijk} k \mathrm{knnop}}$, random residual assumed to be independent normally distributed with mean zero and variance $\sigma_{\mathrm{e}^{2}}^{2}$. The significant fixed effects were used to form contemporary groups, which were included in genetic parameters analysis.

Variance components, heritability and breeding values were estimated using the bivariate mixed animal model using Wombat software [10]. The model can be described in the matrix notation follows:

$$
y=\mathrm{Xb}+\mathrm{Za}+\mathrm{Sm}+\mathrm{Wc}+\mathrm{e}
$$

And the assumptions of the variances were as:

$$
\operatorname{var}\left[\begin{array}{c}
a \\
m \\
c \\
e
\end{array}\right]=\left[\begin{array}{cccc}
A \boldsymbol{\sigma}^{2}{ }_{a} & A \boldsymbol{\sigma}^{2}{ }_{a m} & 0 & 0 \\
A \boldsymbol{\sigma}^{2}{ }_{a m} & A \boldsymbol{\sigma}^{2}{ }_{m} & 0 & 0 \\
0 & 0 & I_{d} \boldsymbol{\sigma}^{2}{ }_{c} & 0 \\
0 & 0 & 0 & \boldsymbol{I}_{\boldsymbol{i}} \boldsymbol{\sigma}^{2}{ }_{\boldsymbol{e}}
\end{array}\right]
$$

Where $y$, a vector of BW or WW observations; $\boldsymbol{b}$, a vector of fixed effects with an incidence matrix $\boldsymbol{X} ; \boldsymbol{a}$, a vector of random animal effects with incidence matrix $Z ; \boldsymbol{m}$, a vector of random dam effects with incidence matrix $S$; $\boldsymbol{c}$, a vector of random permanent environmental effects of dam with incidence matrix $\boldsymbol{W}$; and $\boldsymbol{e}$, a vector of random residual effects. $\boldsymbol{A}$ is the numerator relationship matrix between animals, $\boldsymbol{I}$ is an identity matrix, $\sigma_{a}^{2}$ is direct additive genetic variance, $\boldsymbol{\sigma}_{m}^{2}$ is maternal additive genetic variance, $\boldsymbol{\sigma}_{a m}^{2}$ is the direct $\times$ maternal genetic covariance, $\sigma_{c}^{2}$ is maternal permanent environmental variance, and $\boldsymbol{\sigma}_{e}^{2}$ is residual variance. Direct and maternal genetic trends were estimated by regressing 
yearly mean estimates of breeding value of animal and dam on year of calving.

\section{Principal component analysis}

The principal component (PC) could be used as index to evaluate animals for multiple traits [6]. First, in order to avoid the effect of traits' different scaling and magnitudes, the estimated direct and maternal breeding values obtained for BW and WW were standardized for mean zero and unit variance. The standardization was performed according to Boligon et al [6] as follows: $\mathrm{z}_{\mathrm{i}}=\left(\mathrm{x}_{\mathrm{i}}-\bar{x}\right) / \mathrm{s}_{\mathrm{i}}$, where $\mathrm{z}_{\mathrm{i}}$ is the standardized value of $\mathrm{x}_{\mathrm{i}}$ variable, $\bar{x}$ is the mean of ith trait, and $\mathrm{s}_{\mathrm{i}}$ is the corresponding standard deviation. Then, the standardized estimated breeding values (SEBVs) were used in the PCA performed using FactoMineR package [11] in R software. Generally, the PCA reduces the information contained in estimated direct and maternal breeding values for BWs and WWs in fewer orthogonal latent variables, PCs, with minimal loss of information or variability [6]. In the current study, the PCs explained the highest percentage of variance (i.e with values greater than one eigenvalues) were used. Using the SEBVs in this analysis, each PC can generate a new value, called a principal component score, which is the result of the sum of the SEBVs of each trait weighed by their respective standardized score coefficient (SSC) [12]. Thus, the PC could be used to evaluate animals for multiple traits. The SSC of each SEBV in each principal component were obtained using the following formula:

$$
S S C_{i j}=\frac{\text { eigenvector }_{i j}}{\sqrt{\text { eigenvalue }_{j}}}
$$

Where $\mathrm{SSC}_{\mathrm{ij}}$ is the SSC for SEBV of $i$ th trait in the $j$ th PC. The principal component scores were calculated as follows:

$$
\mathrm{PCS}_{\mathrm{j1}}=\sum_{i=1}^{m} S S C_{i j} S E B V_{i l}
$$

Where $\mathrm{PCS}_{\mathrm{jl}}$ is the principal component score for the $l$ th animal in the jth principal component, SSC $_{i j}$ is the SSC for EBVs of $i$ th trait in the $j$ th $\mathrm{PC}$ and $\mathrm{SEBV}_{\mathrm{il}}$ is the standardised estimated breeding value of the $i$ th trait for the $l$ th animal.

\section{RESULTS AND DISCUSSION}

\section{Environmental factors}

The current study assessed the non-genetic factors affected the growth performance (i.e. BW and WW) in Egyptian buffalo (Table 2). The sex of calf significantly affected ( $\mathrm{p}<$ $0.0001) \mathrm{BW}$ and $\mathrm{WW}(\mathrm{p}<0.05)$ where male calves were heavier at birth and weaning than female calves. These differences due to sex effects were in agreement with reported results by Pandya et al [4] in Surti buffalo. These differenc-
Table 2. Least square means of factors affecting birth and weaning

\begin{tabular}{|c|c|c|}
\hline \multirow{2}{*}{ Effects } & \multicolumn{2}{|c|}{ Trait } \\
\hline & BW & WW \\
\hline \multicolumn{3}{|l|}{ Sex } \\
\hline Male & $36.06^{\mathrm{a}}$ & $95.90^{\mathrm{a}}$ \\
\hline Female & $35.29^{b}$ & $95.36^{b}$ \\
\hline SEM & 0.087 & 0.158 \\
\hline p-values & 0.0001 & 0.017 \\
\hline \multicolumn{3}{|c|}{ Season of calving } \\
\hline Autumn & $35.49^{b}$ & $95.68^{a b}$ \\
\hline Spring & $35.58^{b}$ & $95.45^{\mathrm{b}}$ \\
\hline Summer & $35.68^{a b}$ & $95.28^{b}$ \\
\hline Winter & $35.94^{a}$ & $96.22^{a}$ \\
\hline SEM & 0.126 & 0.228 \\
\hline p-values & 0.025 & 0.035 \\
\hline \multicolumn{3}{|l|}{ Year of calving } \\
\hline 1980-1990 & $35.91^{b}$ & 96.14 \\
\hline $1991-2000$ & $34.73^{d}$ & 95.58 \\
\hline 2001-2009 & $35.38^{c}$ & 95.69 \\
\hline $2010-2018$ & $36.75^{\mathrm{a}}$ & 95.50 \\
\hline SEM & 0.128 & 0.303 \\
\hline p-values & 0.0001 & 0.721 \\
\hline \multicolumn{3}{|l|}{ Herd } \\
\hline 1 & $34.08^{c}$ & 95.78 \\
\hline 2 & $36.29^{\mathrm{a}}$ & 95.32 \\
\hline 3 & $35.07^{b}$ & 95.06 \\
\hline 4 & $34.25^{\mathrm{c}}$ & 95.87 \\
\hline 5 & $36.66^{\mathrm{a}}$ & 96.14 \\
\hline SEM & 0.199 & 0.413 \\
\hline p-values & 0.0001 & 0.076 \\
\hline \multicolumn{3}{|c|}{ Gestation length (d) } \\
\hline$\leq 295$ & $35.44^{\mathrm{C}}$ & 95.57 \\
\hline $296-310$ & $36.01^{a}$ & 96.05 \\
\hline $311-325$ & $35.52^{\mathrm{bc}}$ & 95.32 \\
\hline$>325$ & $35.80^{\mathrm{ab}}$ & 95.48 \\
\hline SEM & 0.129 & 0.229 \\
\hline p-values & 0.040 & 0.092 \\
\hline \multicolumn{3}{|l|}{ Parity } \\
\hline 1 & $32.94^{d}$ & 95.15 \\
\hline 2 & $34.41^{\mathrm{c}}$ & 95.58 \\
\hline 3 & $35.92^{b}$ & 95.74 \\
\hline 4 & $36.13^{b}$ & 95.48 \\
\hline 5 & $37.02^{a}$ & 95.82 \\
\hline SEM & 0.140 & 0.265 \\
\hline p-values & 0.0001 & 0.343 \\
\hline \multicolumn{3}{|l|}{ Dam weight } \\
\hline 1 & $30.29^{e}$ & 95.68 \\
\hline 2 & $33.59^{d}$ & 95.25 \\
\hline 3 & $34.91^{\mathrm{C}}$ & 95.73 \\
\hline 4 & $35.63^{b}$ & 95.28 \\
\hline 5 & $36.99^{\mathrm{a}}$ & 95.81 \\
\hline SEM & 0.178 & 0.304 \\
\hline p-values & 0.0001 & 0.423 \\
\hline
\end{tabular}
weights of buffalo calves

SEM, standard error mean.
${ }^{a-d}$ Values within a column with different superscripts differ at $p<0.05$ 
es are probably due to physiological mechanisms associated with sexual endocrine systems which cause the differences between masculinity and feminist characteristics and the natural buildup of male and female bodies [13]. Season of calving also had a significant $(\mathrm{p}<0.05)$ effect on both BW and WW where the heavier BW and WW buffaloes calves born in winter compared to those born in other seasons confirming the significant effect of season on buffalo calves' growth performance reported in India [4] and Egypt [14]. Such positive effect of winter calving on BW and WW may be due to the appropriate climatic conditions especially temperature, and feeding regimes. Furthermore,, the effect of year of calving on BW had significant effect as in the results stated in other studies [4,14]. The effect of year of calving on BW reflects year to year variability with respect to feeding and management practices and climate changes. Moreover, in the current study, the effect of herd was significant $(\mathrm{p}<$ 0.0001 ) on BW but it did show significant effect on WW. The strong effect of herd may be attributed to differences in management practices among herds during the dam gestation period. Also, Gestation length had a significant effect on BW $(\mathrm{p}<0.05)$ but it did not have effect on WW. The calves having gestation length between 260 to 310 days had the heaviest BW, followed by those having gestation length longer than 325 days whereas the calves having gestation length below 296 days were the lightest BW. These results were in agreement with what reported in other studies on beef cattle by Jamrozik and Miller [15], where they found a positive genetic correlation between BW and GL. The current study found a significant $(p<0.0001)$ effect of parity on BW whereas there was no effect for parity on WW. Calf BW was lower for primiparous buffaloes than those of multiparous. Furthermore, BW of calves increased with parity number. This positive relationship has reported in other studies $[3,13]$. The parity number and age at parturition are reproductive traits which are associated with the physiological status of the female buffaloes and positively effect on calves' BWs. The effect of parity on BW may be due to the maturity status of the dams buffaloes as in the late parities, they have high body capacity compatible with better development of fetus [16]. In the current study we also found that, the WD had the same trend for BW, confirming the results reported in previous studies [17].

\section{Genetic parameters}

The direct heritability estimates were 0.06 and 0.41 for BW and $\mathrm{WW}$, respectively whereas direct maternal heritability values were 0.03 and 0.14 , respectively (Table 3 ). These heritability values are in the range reported for direct heritability of BW ( 0.05 to 0.188$)$ and maternal heritability ( 0.03 to 0.349$)$ on other buffalo populations $[4,18,19]$. The low direct and maternal heritability values for BW due to maternal environ-
Table 3. Variance components and genetic parameters with respective standard error for birth and weaning weights in buffalo calves

\begin{tabular}{lcr}
\hline $\begin{array}{c}\text { Variance } \\
\text { components }\end{array}$ & $\begin{array}{c}\text { BW } \\
\text { (Estimate } \pm S E)\end{array}$ & $\begin{array}{c}\text { WW } \\
\text { (Estimate } \pm S E)\end{array}$ \\
\hline$\sigma_{a}^{2}$ & $5.01 \pm 2.26$ & $164.9 \pm 27.24$ \\
$\sigma_{m}^{2}$ & $2.01 \pm 4.23$ & $55.62 \pm 34.89$ \\
$\sigma_{m}^{a}$ & $-0.52 \pm 2.16$ & $-21.74 \pm 18.64$ \\
$\sigma^{2}$ & $34.96 \pm 4.79$ & $115.80 \pm 27.46$ \\
$\sigma^{2}$ & $35.42 \pm 1.70$ & $87.76 \pm 15.89$ \\
$\sigma^{2}$ & $76.89 \pm 3.21$ & $402.36 \pm 23.43$ \\
$h^{2}$ & $0.06 \pm 0.029$ & $0.41 \pm 0.066$ \\
$h^{2}$ & $0.03 \pm 0.055$ & $0.14 \pm 0.084$ \\
$C^{2}$ & $0.45 \pm 0.053$ & $0.28 \pm 0.068$ \\
$r_{a m}$ & $-0.16 \pm 0.614$ & $-0.23 \pm 0.174$ \\
$r_{g}$ & \multicolumn{2}{c}{$0.06 \pm 0.217$} \\
$r_{m}$ & $0.26 \pm 0.805$ \\
$r_{c}$ & $0.003 \pm 0.127$ \\
\hline
\end{tabular}

BW, birth weights; WW, weaning weights; SE, standard error; $\sigma_{a}^{2}$, direct genetic variance; $\sigma_{m}^{2}$, maternal genetic variance; $\sigma_{a m}$, direct $\times$ maternal genetic covariance; $\sigma_{c}^{2}$, maternal permanent environmental variance; $\sigma_{e}^{2}$, residual variance; $\sigma_{p}^{2}$, phenotypic variance; $h^{2}$, direct heritability; $h_{m,}^{2}$ maternal heritability; $C^{2}$, proportion of phenotypic variance due maternal permanent environmental variance; $h^{2}$, total heritability; $r_{\text {am }}$, genetic correlation between direct $\times$ maternal effect; $r_{g}$, direct genetic correlation between birth and weaning weights; $r_{m}$, maternal genetic correlation between birth and weaning weights; $r_{c}$, maternal permanent environmental correlation between birth and weaning weights.

mental variance being more than 7 folds of direct heritability, can be an indication that genetic selection for BW could be effective, when improving dam feeding and management practices during last phase of pregnancy might play an essential role to increase BW of calves [20]. In Brazilian buffaloes calves, Malhado et al [19] reported low heritability estimates 0.09 and 0.03 for direct and maternal heritabilities, respectively. Also, in Colombian buffalo calves, Bolívar et al [21] found low direct and maternal heritability estimates of 0.05 and 0.01 respectively. On the other hand, Pandya et al [4] and Gupta et al [18] obtained heritability values of 0.188 and 0.349 , respectively, for BW of Surti Murrah buffalo. Although, the heritability estimates are population specific, the high estimates reported in Surti buffalo were probably attributed to the use of animal model without accounting for maternal effects which may overestimate the direct heritability estimates. In this study, we found a negative correlation between direct and maternal $\left(\mathrm{r}_{\mathrm{am}}\right)$ effects for BW $(-0.16)$ which was reported by other studies [22]. This negative genetic correlation could be due to another negative correlation between dam and calf resulted from an adverse effect of high nutrition during early growth of calf [22].

In the current study, high (0.41) and moderate (0.14) direct and maternal heritability estimates were obtained for WW, respectively indicating that the genetic selection to improve $\mathrm{WW}$ is possible with good response of maternal ability [23]. Such lower estimate of maternal heritability than direct 
heritability indicated that the direct genetic effect has large influence on WWs in buffaloes [21]. The current heritability estimates for WW are in agreement with estimated reported in Brazilian buffalo. Nonetheless, the current estimates were higher than direct heritability estimate reported by Ashmawy and El-Bramony [24] (0.19) in Egyptian buffalo, and Pandya et al [4] (0.17) in Surti buffalo. Also, in Colombian buffalo, found direct and maternal heritability values of 0.16 and 0.04 , respectively [8]. The variation in WW due to maternal environment was moderate but smaller than its value for BW, indicating that the permanent environmental influence of dam on WW has a carryover effect from birth to weaning [25]. The current results showed that the proportion of phenotypic variance due maternal permanent environmental variance $\left(C^{2}\right)$ was higher than $\mathrm{h}_{\mathrm{m}}^{2}$ for BW and $\mathrm{WW}$, indicating that maternal environmental effect was dominant until weaning [23]. Estimates of $\mathrm{C}^{2}$ and $\mathrm{h}_{\mathrm{m}}^{2}$ for different beef breeds were close to those obtained in the current study [26]. The direct-maternal genetic correlation $\left(\mathrm{r}_{\mathrm{am}}\right)$ was negative for $\mathrm{WW}$ and higher than its value for BW. This negative $r_{a m}$ was also found in Australian beef cattle [22] and Spanish beef cattle [27]. The negative genetic correlation may be due to a negative correlation between dam and calf resulted from an adverse effect of the high nutrition during early growth of calf [22].

A low genetic correlation between BW and WW (0.05) found in the current study indicated that selection to improve WW in buffalo may not affect BW in a breeding objectives that include both traits. Such relationship is very important to avoid dystocia which may occur for calves with high BW. High estimates of genetic correlation between BW and WW of Egyptian buffalo calves were reported in other studies [18] using animal model which did not account for maternal effects. The estimates genetic correlation between growth traits in Beef cattle are usually moderate to high $[3,25,27]$, but others were low and negative such as those by El-Saied et al [28]. The weak correlation between BW and WW may be a decrease in correlation response because of a decrease in selection intensity and population size [29]. Thus, the low genetic correlation in current study may be attributed to low selection intensity in Egyptian buffalo populations compared to beef cattle. In this study, the maternal genetic $r_{m}$ and maternal permanent environmental $r_{c}$ correlations were 0.262 and 0.003 respectively which were lower than estimated values 0.33 and 0.64 reported in Japanese beef cattle [25].

Remarkable fluctuations in breeding values of calves and dams, and negative direct and maternal genetic trend in some years were found (Figure 1). Averages of direct and maternal genetic trend were $-0.003,0.002,-0.020$, and $0.001 \mathrm{~kg} / \mathrm{yr}$ for BW and WW, respectively indicating that there was no specific breeding programs have been applied to improve growth traits in the studied buffalo herds. Therefore, there was no genetic improvement in either trait. Other studies showed improvement in $\mathrm{BW}$ and $\mathrm{WW}$ where the direct and maternal genetic trends for BW and WW of Brazilian buffalo were $0.006,-0.01,0.23$, and $0.05 \mathrm{~kg} / \mathrm{yr}$, respectively [19]. Nonetheless, a negative direct genetic trend was $-0.03 \mathrm{~kg} / \mathrm{yr}$ was reported for water buffalo in Brazil [30].

\section{Principal components}

The total variance explained by PCs was $71.17 \%$ in which $45.91 \%$ and $25.25 \%$ were explained by PC1 and PC2, respectively (Table 4). These results indicated that the first two PCs out of 4 showed eigenvalues greater than 1 . Therefore, the first two components were sufficient to explain the most of variation in breeding value estimates for early growth traits

Table 4. Eigenvalues and variance proportions for the principal components of the standardized breeding values

\begin{tabular}{lccc}
\hline $\begin{array}{l}\text { Principal } \\
\text { components }\end{array}$ & Eigenvalue & Variance (\%) & $\begin{array}{c}\text { Cumulative } \\
\text { variance (\%) }\end{array}$ \\
\hline 1 & 1.836 & 45.91 & 45.91 \\
2 & 1.01 & 25.25 & 71.17 \\
3 & 0.743 & 18.59 & 89.76 \\
4 & 0.409 & 10.23 & 100 \\
\hline
\end{tabular}

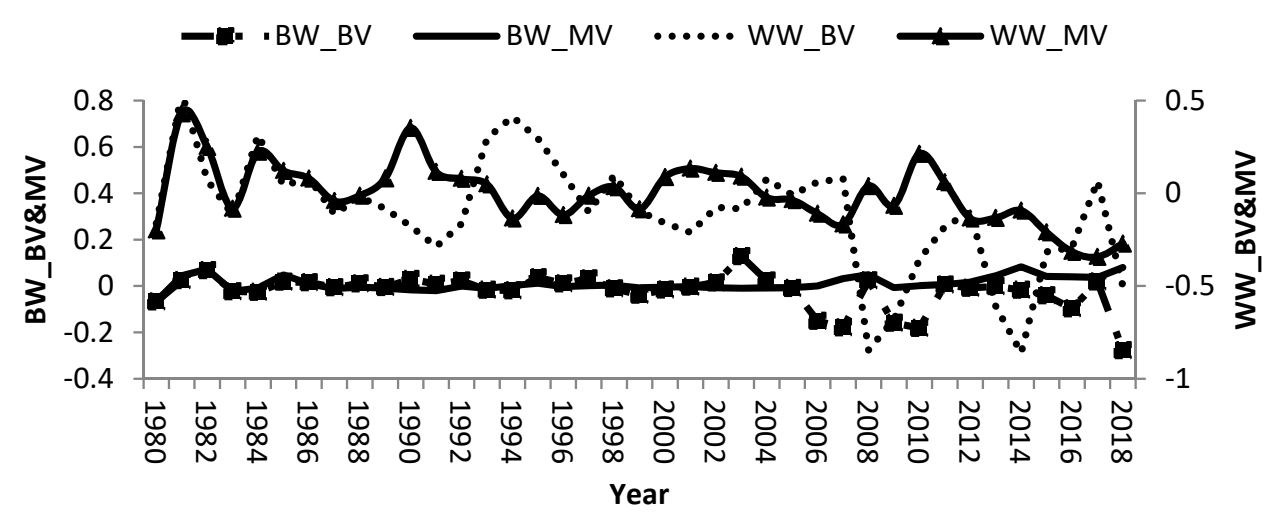

Figure 1. Direct and maternal genetic trends of birth and weaning weights in buffalo. 
Table 5. Correlation coefficients between standardized breeding values of the studied traits with the first 2 principal components

\begin{tabular}{lcr}
\hline Trait & PC1 & PC2 \\
\hline BW_BV & -0.370 & 0.82 \\
BW_MV & 0.64 & -0.35 \\
WW_BV & -0.77 & -0.38 \\
WW_MV & 0.84 & 0.28 \\
\hline
\end{tabular}

PC, principal component; BW_BV, direct breeding of birth weight; BW_MV, maternal breeding value of birth weight; WW_BV, direct breeding value of weaning weight; WW_MV, maternal breeding value of weaning weight.

in the current buffalo calves herds. The variation in breeding values for growth traits have been studied by Boligon et al [31] where they found the first three PCs explained 93.62\% of total additive genetic variation of growth traits in Nellore cattle. In Colombian buffalo, three PCs greater explained $65.87 \%$ of the variance of breeding value for growth traits [8]. The two-dimensional graph of PC1 vs PC2 (Figure 2) and the correlation between $\mathrm{BV}, \mathrm{MV}$ of both traits and $\mathrm{PC}$ (Table 5) showed that the direct breeding values of $\mathrm{BW}$ were correlated with PC2 and those for direct and maternal breeding values of $\mathrm{BW}$ and WW were correlated with $\mathrm{PC}$.

PC1 explained most of direct and maternal breeding value variation and was correlated with the direct and maternal breeding values of WW and maternal breeding values of BW. Thus, it could be considered as genetic index to WW and also as maternal index for BW and WW. Only $25.25 \%$ of direct and maternal breeding value variation was explained by PC2 which was correlated with direct breeding values of BW and considered as genetic index related BW. Therefore, se- lection to improve WW could be applied using PC1 separate from selection to improve BW in Egyptian buffalo. These results supported the reported genetic correlation between BW and WW in Table 3. The two-dimensional graph of PC1 vs PC2 illustrated in Figure 2, showed a negative correlation between maternal and genetic breeding value of $\mathrm{BW}$ and $\mathrm{WW}$ supported the direct-maternal genetic correlations reported in Table 3. A study, on Canchim cattle, reported similar trends where the first two principal components explained $73.37 \%$ of total additive genetic variance, and the PC1 was considered as genetic index for reproduction traits as well as PC2 was a genetic index correlated with body weight [12].

The PC scores for each animal in the first two principal components were calculated as:

$$
\begin{aligned}
\text { PCS1 }= & -0.273 \mathrm{BV}_{\mathrm{BW} \_\mathrm{BV}}+0.472 \mathrm{BV}_{\mathrm{BW} \_\mathrm{MV}} \\
& -0.568 \mathrm{BV}_{\mathrm{WW} \_\mathrm{BV}}+0.620 \mathrm{BV}_{\mathrm{WW} \_\mathrm{MV}} \\
\text { PCS2 }= & 0.811 \mathrm{BV}_{\mathrm{BW} \_\mathrm{BV}}-0.346 \mathrm{BV}_{\mathrm{BW} \_\mathrm{MV}} \\
& -0.376 \mathrm{BV}_{\mathrm{WW} \_\mathrm{BV}}+0.277 \mathrm{BV}_{\mathrm{WW} \_\mathrm{MV}}
\end{aligned}
$$

The weights of these indices were SSC for each SEBV. The larger the absolute value of the SSC, the greater the relative importance. The 2 PC scores allowing capture the main information in predicted breeding value for $\mathrm{BW}$ and $\mathrm{WW}$. Animals with higher PCS1 could be used to improve WW, and animals with higher PCS2 could be used to improve BWs. Thus, selection with previous index could be used in genetic selection programs of Egyptian buffalo. As previously mentioned regarding the use of PCA is very practical

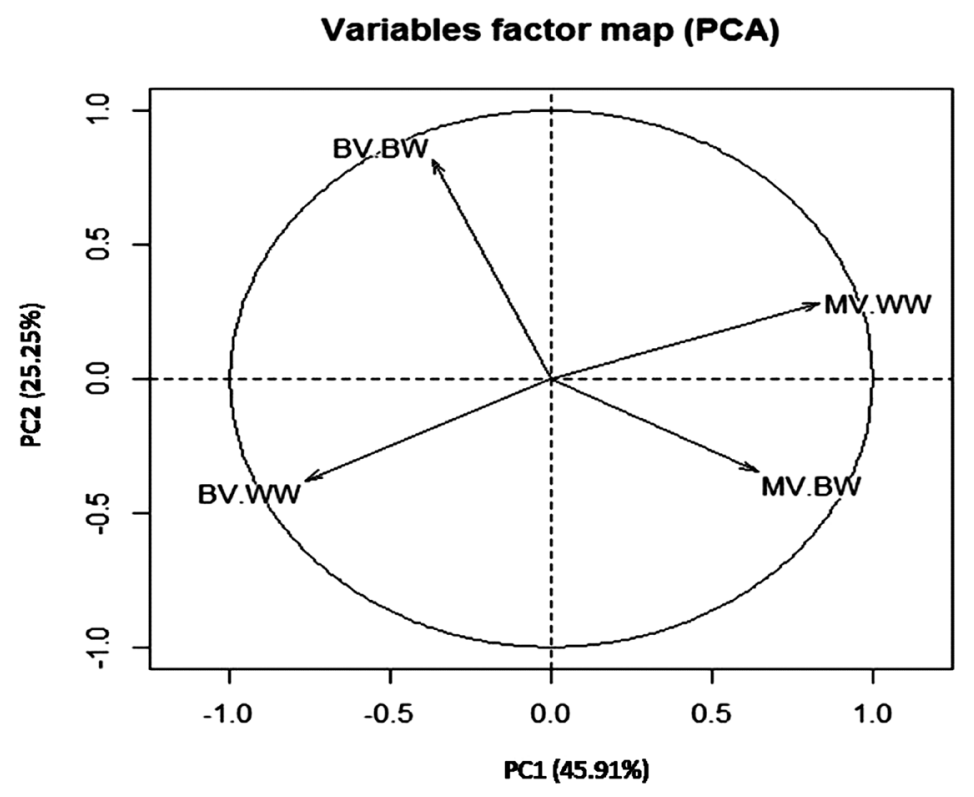

Figure 2. Distribution of the traits analyzed in each of the first two principal components PC1 vs PC2. BV-BW, direct breeding of birth weight; MV-BW, maternal breeding value of birth weight; BV-WW, direct breeding value of weaning weight; MV-WW, maternal breeding value of weaning weight. 
technique to reduce the data dimensionality especially with limited number of observations in the dependent variables under the lacking of national recording system in Egypt. Also, under Egyptian breeding programs, it has been difficult to develop the economic indices and if developed they were rarely used because of the difficulty in economic weights for each trait as the Egyptian market is not stable. Thus, we can consider the PCSs as new traits which can be included in new breeding objectives and used as selection criteria under Egypt condition. Meanwhile, in other studies the PCSs can be used to reduces the genetic variance components accounting for selection bias and correlated response in correlated traits [32].

\section{CONCLUSION}

All environmental factors affect BW, and sex, season of calving and herd affected on WW. The results indicated low heritability value for BW, high heritability value for WW and low genetic correlation between BW and WW. Moreover, 2 PCs components were sufficient to capture the breeding value variation of the studied traits. Finally PC1 and PC2 could be considered as new traits representing WW and BW, respectively. These results suggested improving growth traits of Egyptian buffaloes could be achieved using WW without any adverse effect by BW.

\section{CONFLICT OF INTEREST}

We certify that there is no conflict of interest with any financial organization regarding the material discussed in the manuscript.

\section{REFERENCES}

1. FAOSTAT. FAO Statistics Division. Rome, Italy: FAO; 2016.

2. Salem MMI, Amin AMS. Risk factors and genetic evaluation of stillbirth trait in buffalo. Livest Sci 2017;206:132-4. https:// doi. org/10.1016/j.livsci.2017.10.020

3. Akhtar P, Kalsoom U, Ali S, et al. Genetic and phenotypic parameters for growth traits of Nili-Ravi buffalo heifers in Pakistan. J Anim Plant Sci 2012;22:347-52.

4. Pandya GM, Joshi CG, Rank DN, et al. Genetic analysis of body weight traits of Surti buffalo. Buffalo Bulletin 2015;34: 189-95.

5. Suhail SM, Qureshi MS, Khan S, Sanullah IH, Durrani FR. Inheritance of economic traits of dairy buffaloes in Pakistan. Sarhad J Agric 2009;25:87-93.

6. Boligon AA, Vicente IS, Vaz RZ, et al. Principal component analysis of breeding values for growth and reproductive traits and genetic association with adult size in beef cattle. J Anim Sci 2016;94:5014-22. https://doi.org/10.2527/jas.2016-0737
7. Agudelo-Gómez DA, Savegnago RP, Buzanskas ME, Ferraudo AS, Munari DP, Cerón-Muñoz MF. Genetic principal components for reproductive and productive traits in dual-purpose buffaloes in Colombia. J Anim Sci 2015;93:3801-9. https:// doi.org/10.2527/jas.2015-8940

8. Agudelo-Gómez D, Pineda-Sierra S, Cerón-Muñoz MF. Genetic evaluation of dual-purpose buffaloes (Bubalus bubalis) in Colombia using principal component analysis. Plos One 2015;10:e0132811. https://doi.org/10.1371/journal.pone. 0132811

9. SAS. SAS/STAT Software. Release 9.3, Cary, NC, USA: SAS Institute, Inc; 2012.

10. Meyer K. WOMBAT - Digging deep for quantitative genetic analyses by restricted maximum likelihood. Proc. 8th World Congress of Genetics Applied for Livestock Production; 2006. Communication No. 27-14.17.

11.Lê S, Josse J, Husson F. FactoMineR: a package for multivariate analysis. J Stat Softw 2008;25:1-18. https://doi.org/10.18637/ jss.v025.i01

12. Buzanskas ME, Savegnago RP, Grossi DA, et al. Genetic parameter estimates and principal component analysis of breeding values of reproduction and growth traits in female Canchim cattle. Reprod Fertil Dev 2012;25:775-81. https://doi.org/10. 1071/RD12132

13. Thiruvenkadan AK, Panneerselvam S, Rajendran R. Nongenetic and genetic factors influencing growth performance in Murrah Buffalos. S Afr J Anim Sci 2009;39 (Suppl 1):1026. https://doi.org/10.4314/sajas.v39i1.61326

14. Salem MMI, Hammoud MH. Estimates of heritability, repeatability and breeding value of some performance traits of Holstein cows in Egypt using repeatability animal model. Egyptian J Anim Prod 2016;53:147-52.

15. Jamrozik J, Miller SP. Genetic evaluation of calving ease in Canadian Simmentals using birth weight and gestation length as correlated traits. Livest Sci 2014;162:42-9. https://doi.org/ 10.1016/j.livsci.2014.01.027

16. Ahmad M, Javed K, Rehman A. Environmental factors affecting some growth traits in Nili-Ravi buffalo calves. 7th World Congress on Genetics Applied to Livestock Production; 2002 Aug 19-23: Montpellier, France.

17.Lopes CRdA, Barbosa SBP, Pereira RGdA, Santoro KR, Lira AVd. Reproductive performance, genetic and environmental effects on birth weight of Buffaloes in Rondonia State. R Bras Zootec 2008;37:1595-600. https://doi.org/10.1590/S1516-359 82008000900010

18. Gupta JP, Sachdeva GK, Gandhi RS, Chakaravarty AK. Developing multiple-trait predection models using growth and production traits in Murraha buffalo. Buffalo Bulletin 2015;34: 347-55.

19. Malhado M, Ramos A, Carneiro S, de Souza JC, Lamberson WR. Genetic and phenotypic trends for growth traits of buffaloes in Brazil. Ital J Anim Sci 2007;6:325-7. https://doi. 
org/10.4081/ijas.2007.s2.325

20.Gowane GR, Chopra A, Prakash V, Prince LLL. The role of maternal effects in sheep breeding: a review. Ind J Small Rumin 2014;20:1-11.

21. Bolívar DM, Cerón-Muñoz MF, Boligon AA, Elzo MA, Herrera AC. Genetic parameters for body weight in buffaloes (Bubalus bubalis) in Colombia using random regression models. Livest Sci 2013;158:40-9. https://doi.org/10.1016/j.livsci.2013.10. 015

22. Meyer K. Variance components due to direct and maternal effects for growth traits of Australian beef cattle. Livest Prod Sci 1992;31:179-204. https://doi.org/10.1016/0301-6226(92) 90017-X

23. Meyer K. Estimates of direct and maternal covariance functions for growth of Australian beef calves from birth to weaning. Genet Sel Evol 2001;33:487. https://doi.org/10.1186/12979686-33-5-487

24. Ashmawy AA, El-Bramony MM. Genetic association for some growth and reproductive traits in primiparous buffalo females. Int J Genet 2017;7:25-30.

25. Aziz MA, Nishida A, Suzuki K, Nishida S. Estimation of direct and maternal genetic and permanent environmental effects for weights from birth to 356 days of age in a herd of Japanese Black cattle using random regression. J Anim Sci 2005;83: 519-30. https://doi.org/10.2527/2005.833519x

26. Meyer K. Estimates of genetic parameters for weaning weight of beef cattle accounting for direct-maternal environmental covariances. Livest Prod Sci 1997;52:187-99. https://doi.org/ 10.1016/S0301-6226(97)00144-9

27. Gutiérrez JP, Goyache F, Alvarez I, Fernández I, Royo LJ. Genetic relationships among calving ease, calving interval, birth weight, and weaning weight in the Asturiana de los Valles beef cattle breed. J Anim Sci 2007;85:69-75. https:// doi.org/10.2527/jas.2006-168

28.El-Saied UM, Fuente LF, Rodríguez R, Primitivo FS. Genetic parameter estimates for birth and weaning weights, preweaning daily weight gain and three type traits for Charolais beef cattle in Spain. Span J Agric Res 2006;4:146-55.

29. Eisen EJ, Hanrahan JP, Legates JE. Effects of population size and selection intensity on correlated responses to selection for postweaning gain in mice. Genetics 1973;74:157-70.

30. Aguiari JFd, Marcondes CR, Marques JRF, et al. Genetic variability of birth weight and selection for growth of water buffaloes from State of Pará, Brazil. Acta Amazon 2014;44: 373-8.

31. Boligon AA, Bignardi AB, Mercadante MEZ, Lobo RB, Albuquerque LG. Principal components and factor analytic models for birth to mature weights in Nellore cattle. Livest Sci 2013; 152:135-42. https://doi.org/10.1016/j.livsci.2013.01.005

32. Meyer K. Multivariate analyses of carcass traits for Angus cattle fitting reduced rank and factor analytic models. J Anim Breed Genet 2007;124:50-64. https://doi.org/10.1111/j.1439-0388. 2007.00637.x 